\title{
Impact of COVID-19 pandemic and related isolation measures on violence against children in Egypt
}

\author{
Seham Ahmed AboKresha ${ }^{1 *}$, Elsayed Abdelkreem ${ }^{2}$ and Rasha Abd Elhameed Ali ${ }^{1}$
}

\begin{abstract}
Background: Coronavirus disease 2019 (COVID-19) and related isolation measures have substantial adverse economic, social, and psychological consequences and expose children to increased risk of violence. The present study aimed to investigate the impact of the COVID-19 pandemic on violence against children in Egypt.

Methods: An online survey, in Arabic, was disseminated during the period from 9 to 13 April 2020, to parents of children who were up to 18 years old residing in Egypt, selected using a snowball sampling technique, during the period from 25 March to 8 April during the implementation of the nationwide compulsory isolation measures against COVID-19 (25 March to 8 April 2020). The survey covered three areas: socio-demographic data, psychological impact measured using the Impact of Event Scale-Revised (IES-R), and violence against children during the past 2 weeks measured using a modified parent-report of a child abuse screening tool (ICAST-P) developed by the International Society for the Prevention of Child Abuse and Neglect.

Results: Out of 1118 completed survey responses, 90.5\% of children were subjected to violent discipline, 88.7\% experienced psychological aggression, and $43.2 \%$ encountered severe physical punishment. Approximately $60 \%$ of respondents reported a moderate-to-severe psychological impact (IES-R scores $\geq 33$ ), which was associated with a higher rate of violent discipline (OR: 9.3; 95\% Cl: 5.37-16.027; $p<0.001$ ).

Conclusions: This is the first study in Egypt to provide evidence on the association of COVID-19 pandemic, its psychological impact, and increased rates of violence against children. Effective multilevel strategies are urgently required to protect children from violence and its catastrophic consequences during the continually evolving COVID-19 pandemic.
\end{abstract}

Keywords: Violence against children, Child maltreatment, COVID-19, Isolation measures, Post-traumatic stress disorder

\section{Introduction}

Coronavirus disease 2019 (COVID-19) is an emerging and rapidly evolving major public health challenge for the entire global population. COVID-19 was first reported in December 2019 in Wuhan City (Hubei Province, China) and has been rapidly spreading to affect millions worldwide. Beyond the health crisis, COVID-19

\footnotetext{
* Correspondence: Sehamghalib85@gmail.com

'Public Health and Community Medicine Department, Sohag University, Sohag, Egypt

Full list of author information is available at the end of the article
}

has major adverse economic, social, and psychological consequences $[1,2]$.

To limit the spread of COVID-19, countries have implemented variable control measures up to complete lockdown, including school closures [3]. The United $\mathrm{Na}$ tions Educational, Scientific and Cultural Organization (UNESCO) estimates that over 1.5 billion children are out of schools and childcare centers because of COVID19 lockdown [4]. Consequently, families have been confined at home with their children. These circumstances have had negative psychological effects and exposed the

\section{Springer Open}

(ㅇ The Author(s). 2021 Open Access This article is licensed under a Creative Commons Attribution 4.0 International License, which permits use, sharing, adaptation, distribution and reproduction in any medium or format, as long as you give appropriate credit to the original author(s) and the source, provide a link to the Creative Commons licence, and indicate if changes were made. The images or other third party material in this article are included in the article's Creative Commons licence, unless indicated otherwise in a credit line to the material. If material is not included in the article's Creative Commons licence and your intended use is not permitted by statutory regulation or exceeds the permitted use, you will need to obtain permission directly from the copyright holder. To view a copy of this licence, visit http://creativecommons.org/licenses/by/4.0/. 
children to an increased risk of violence with its potential adverse consequences on their future life [5-8].

Violence against children, encompassing all forms of violence against individuals under 18 years of age, is an important public health, human right, and social concern. Child maltreatment includes physical, psychological, and sexual abuse and neglect by parents or other legal caregivers. A systematic review in 2016 estimated that up to 1 billion children aged 2-17 years' experience different forms of violence every year globally [9]. Children exposed to violence may suffer from significant lifelong adverse consequences, which extend to families, societies, and countries $[10,11]$. Under the United Nations Convention on the Rights of the Child, children all over the world have the right to be safe from violence. The 2014 Egyptian Constitution and Article 1 of the 2008 Egyptian Child Law guaranteed that right for children [12]. In Egypt, a 2014 UNICEF study on violence committed against children in Cairo, Alexandria, and Assiut found that two-thirds of youngsters within the areas covered had been subjected to physical abuse, and $78 \%$ were victims of emotional violence [12].

Previous studies reported increased rates of psychological distress and violence against children during wide-scale health emergencies, including outbreaks of infections, associated with school closure and social isolation [13]. To date, there has been no adequate information on violence against children during the COVID19 pandemic $[6,13]$.
Timely knowledge and understanding of the impact of the COVID-19 pandemic and related isolation measures on violence against children are urgently required to provide updated information for the society, healthcare system, and national authorities $[6,8]$. The aim of the present study was to identify the magnitude, pattern, and risk factors of violence against children and its association with parents' psychological stress during the period of the isolation measures related to the COVID19 pandemic in Egypt.

\section{Methods}

\subsection{Study Setting, design, and participants}

Egypt is a developing country with approximately 100 million inhabitants living in an area of 1.01 million $\mathrm{km}^{2}$. The national trend of the COVID-19 epidemic in Egypt is illustrated in Fig. 1. Since the identification of the first case of COVID-19 in Egypt on February 13, 2020, the numbers of confirmed cases, convalescent individuals, and deaths attributed to COVID-19 infection have continued to increase, with a significant rise since the beginning of April 2020. COVID-19 has affected all age groups from all Egyptian areas, but most deaths were among elderly people with medical comorbidities. National precautionary actions against COVID-19 in Egypt started by school closure (March 15, 2020) and extended to nationwide lock down (March 25, 2020) [14].

This cross-sectional study was conducted between February and April 2020. Eligible participants were Egyptian parents of children up to 18 years old who

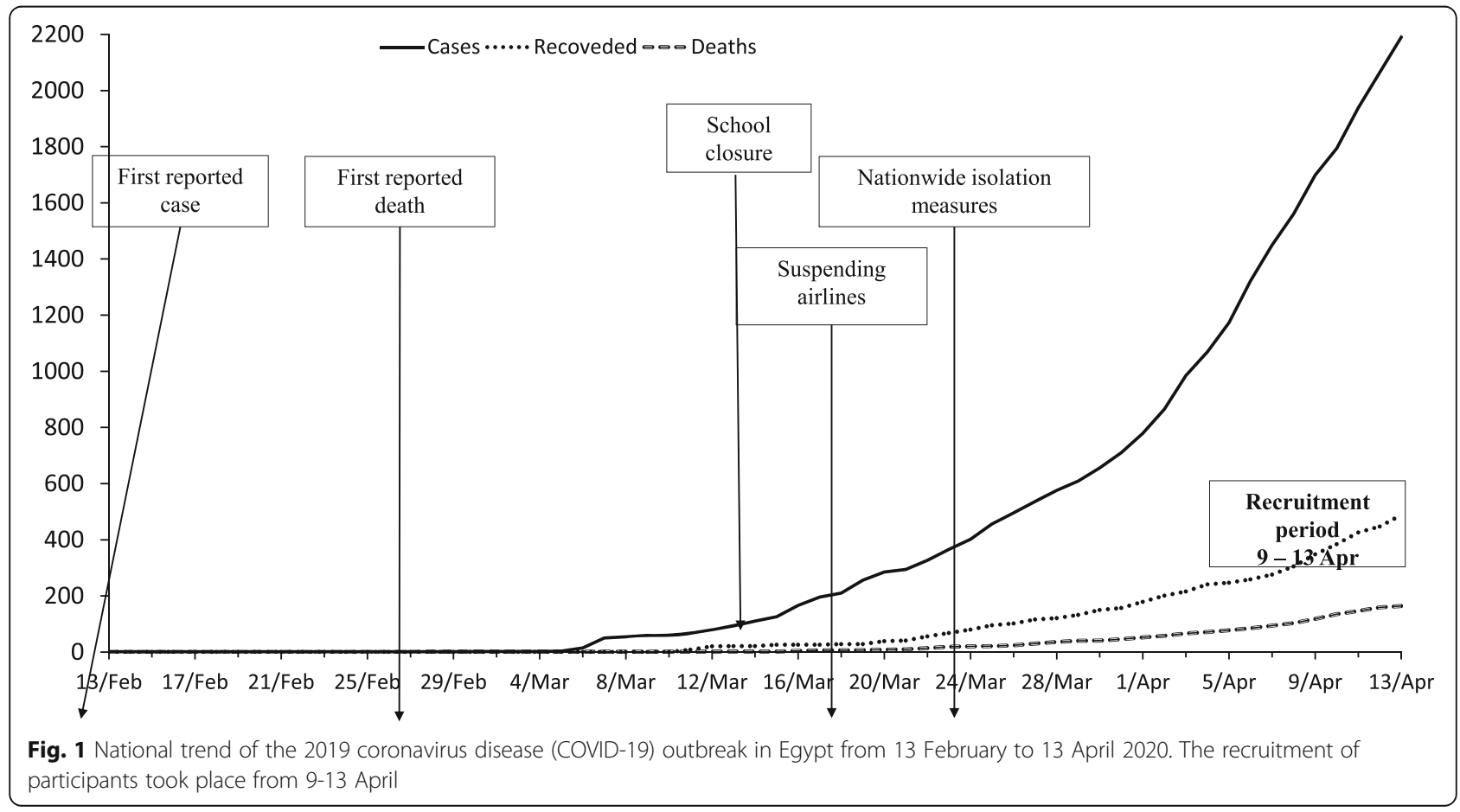


were residing in Egypt during the first 2 weeks of implementing the nationwide compulsory isolation measures against COVID-19 (from 25 March to 8 April 2020). We adopted a snowball sampling technique to recruit potential participants.

The sample size was calculated using the Epi Info program developed by Centers for Disease Control and Prevention (CDC) in Atlanta, Georgia (US) version7 software, based on the following assumptions: a $68 \%$ prevalence of violence against children, as reported by a 2014 UNICEF study [12]; 95\% level of confidence and $5 \%$ precision; and 1 as design effect 1 . The calculated minimum sample size was 364 . For proper representation of the Egyptian community, recruitment was opened for 2 weeks to maximize the sample size. A total of 1191 responses were submitted to the web-based survey, but missing data led to the exclusion of 73 responses. Ultimately, 1118 completed questionnaires were included in the analysis. We received 42 completed responses on the first day, 384 on the second day, 435 on the third day, 251 on the fourth day, and only 6 on the fifth day. The average time to complete the survey was $18 \mathrm{~min}$

\subsection{Data collection method}

We used a web-based methodology for survey design, dissemination, and data collection because the Egyptian government imposed compulsory nationwide isolation measures and asked the public to minimize direct personal contact and isolate themselves at home. We prepared an anonymous electronic survey using the Microsoft forms (http://forms.office.com) and distributed it to the general Egyptian population using multiple means of communication and social media, such as Facebook, Twitter, Instagram, and WhatsApp. The webbased survey was also sent to university students who were encouraged to disseminate it to other people (friends, family members, and relatives). Potential participants for this study were invited by other study respondents through an electronic link to the survey. Respondents completed the anonymous electronic questionnaire in Arabic. Data collection occurred over 5 days (9-13 April 2020).

\subsection{Validation of the study tools}

The psychological impact of COVID-19 on survey respondents was assessed using the Impact of Event ScaleRevised (IES-R), and violence against children was assessed by the parent-report version of the International Society for the Prevention of Child Abuse and Neglect (ISPCAN) child abuse screening tool (ICAST-P) [15]. Both questionnaires were translated into Arabic according to the standard guidelines of translation and cultural adaptation of psychological and educational tests
[16]. First, forward translation was carried out by two independent bilingual, bicultural professional translators who are native Arabic speakers. A consensus version of the scale was reached, which was reviewed by external experts. Second, back translation of the first translated version into English was performed by another bilingual, bicultural professional translator who is a native English speaker (with no access to the original English version), followed by comparison with the original English source to produce the second translated version. Third, face validity was conducted through an online cognitive interview with 50 potential Egyptian participants of different educational levels to evaluate understanding, interpretation, and appropriateness of each item. Reliability of both questionnaires was tested using the Cronbach's alpha. The Cronbach's alpha coefficient was 0.89 for IES-R and 0.88 for the adopted ICAST-P.

\subsection{Survey development}

The survey covered three areas: socio-demographic data, the psychological impact of COVID-19 pandemic on parents, and violence against children during the study period.

Socio-demographic data included respondents' gender, age, marital status, educational level, residence, employment status, monthly income, and number of children and whether the children had chronic diseases.

The psychological impact of COVID-19 on survey respondents was assessed using IES-R, which measures the subjective response of adults to a certain potentially stressful life event. IES- $\mathrm{R}$ is an internationally validated, non-cultural specific, self-administered questionnaire, which is composed of 22 items on a five-point Likert scale (where $0=$ not at all, and $4=$ extremely) with three subscales: intrusion (inability to keep memories of the event from returning), avoidance (an attempt to avoid stimuli and triggers that may bring back those memories), and hyper arousal (a primary symptom of posttraumatic stress disorder (PTSD) that occurs when a person's body suddenly kicks into high alert as a result of thinking about their trauma). This instrument (IES-R) is designed to capture the American Psychiatric Association Diagnostic and Statistical Manual of Mental Disorders criteria for PTSD [17]. We used a cut-off score of $\geq 33$ because it was reported to have good diagnostic power (0.88) for PTSD [18].

Violence against children was assessed by the Arabic parent-report version of ICAST-P [15]. The original ICAST-P asks parents about disciplinary practice and omission of care (non-violent, moderate physical, severe physical, psychological, neglect, and sexual abuse) toward a randomly selected index child under 18 years. It measures lifetime and past-year abusive exposure and neglect (once a week or more, several times a month, 
about once a month, several times a year, once or twice a year, not in the past-year, or never); hence, it was not appropriate in the present time-sensitive study. To overcome the long reporting time-frame, Meinck et al. previously designed ICAST-Trial to estimate the actual number of abusive incidents in the past month $(0,1,2$, $3,4,5,6,7$, or $8+$ ) for evaluating the effectiveness of parenting programs [19]. We adopted a similar approach through changing the response codes and reporting time-frame to estimate the actual number of violent incidents ( 0 was assigned to not at all; 1 , to once; 2 , to $2-3$ times; 3 , to $4-7$ times; and 4 , to $>7$ times) in the past 2 weeks. The neglect subscale and two items of the psychological discipline subscale (locking out of the house and public humiliation) were excluded because of contextual consideration (COVID-19 pandemic and related isolation measures). During the step of face validity (interviewing nine potential study participants online), two items of sexual abuse were considered inappropriate and unacceptable; therefore, they were also excluded. The final modified version of ICAST-P used in this study included 35 items with four subscales: non-violent discipline (5 items), moderate physical discipline (12 items), severe physical discipline (8 items), and psychological discipline (10 items). In addition, there were general questions on the index child's age, gender, birth order, and educational level.

\subsection{Ethical approval}

The study was approved by the Research Ethics Committee of the Faculty of Medicine, Sohag University, and was carried out in accordance with the principles of the 1964 Declaration of Helsinki and its 2013 revision. Informed consent was obtained from the respondents by submitting the consent statement included in the survey.

\subsection{Statistical analysis}

Survey data were analyzed using the IBM SPSS ${ }^{\circ}$ software version 20 (IBM SPSS Statistics, New York, USA). Descriptive statistics were presented as frequencies and percentages for categorical variables and mean \pm standard deviation for continuous variables. Chi-squared and odds ratio tests and multivariate logistic analysis were used for calculating the association between sociodemographic parameters, the psychological impact (using an IES-R cut-off score $\geq 33$ ), and violent discipline. All calculations were based on alpha $5 \%$ and beta $80 \%$. A $p$ value (two-tailed) $<0.05$ was considered to be statistically significant.

\section{Results}

Descriptive statistics of the study variables are presented in Tables 1 and 2. Participants' ages ranged between 20 and $\geq 50$ years; most respondents were mothers $(88.1 \%)$, who were currently married (95.3\%), urban residents $(80.6 \%)$, employed at a government agency $(66.3 \%)$, welleducated (bachelors and postgraduate, 97.7\%), and had monthly income $\leq 3000$ Egyptian pounds (53.1\%). Most of them (72.3\%) had two to three children, with no chronic medical conditions among children (93.5\%) and no other persons living with the family in the same household (65.6\%). Most of the included index children were males $(60.6 \%)$, aged $2-12$ years $(75.7 \%)$, of first birth order (79.7\%), and in kindergarten/primary school (69.8\%). As listed in Table 1, rates of reported violent discipline among parents were significantly associated with the female gender, age 30 to 50 years, urban residence, a family income $\geq 3000$ Egyptian pounds, less children, and presence of other individuals living with the family. Certain socio-demographic characteristics were associated with an increased risk of PTSD among parents, including the female gender and age groups 20 to $<50$ years with private work and a monthly income $\leq 3000$ Egyptian pounds, as presented in Table 1.

Regarding the psychological impact of COVID-19, the mean IES-R score of survey respondents was $35.65( \pm 12.92)$. More than half of the respondents (57.8\%) had scores $\geq 33$, indicating a moderate-tosevere psychological impact, which is consistent with PTSD (Table 2). Among the studied children, male children, those aged $<2,2-5$, and $5-8$ years; those with a birth order of $2-3$; and those with kindergarten, primary, and preparatory levels of education, were more exposed to violence.

As shown in Table 3 and Fig. 2, the majority of children $(90.5 \%)$ were subjected to at least one form of violent discipline in the past 2 weeks, $88.7 \%$ experienced psychological aggression, and $43.2 \%$ underwent severe physical punishment. Non-violent discipline was practiced by most participants. For detailed information of each subcategories of violent discipline, see Table 3.

Table 4 displayed the final model of logistic regression analysis of the psychological impact of COVID-19 on parents and practicing different types of violent discipline against their children after adjustment of other socio-demographic variables. It shows that there was a strong association between psychological impact of COVID-19 pandemic on parents and practicing violence against their children. Children to parents with probable PTSD were nine times more exposed to violent discipline than those to parents with no/mild psychological impact.

\section{Discussions}

This is the first study in Egypt to investigate the impact of the COVID-19 pandemic and related isolation measures on violence against children. Through surveying 
Table 1 Socio-demographic characteristics of survey respondents and their association with psychological impact of the pandemic on the parents and violent discipline against their children during the COVID-19 pandemic in Sohag governorate, Egypt, 2020

\begin{tabular}{|c|c|c|c|c|c|c|c|}
\hline Parameters & $\begin{array}{l}\text { Parents } \\
\text { respondents } \\
N=1118(\%)\end{array}$ & $\begin{array}{l}\text { Parents' IES-R score } \geq \\
33 \\
N=646(\%)\end{array}$ & OR & $p$ & $\begin{array}{l}\text { Parents' violent } \\
\text { discipline } \\
N=1012 .(\%)\end{array}$ & OR & $p$ \\
\hline \multicolumn{8}{|l|}{ Parents' gender } \\
\hline Male ${ }^{\circledR}$ & $133(11.9)$ & $60(45.1)$ & & & $108(81.2)$ & & \\
\hline Female & $985(88.1)$ & $586(59.5)$ & 0.56 & 0.002 & $904(91.8)$ & 0.387 & 0.00 \\
\hline Parents' age (years) & & $\begin{array}{l}\mathrm{OR}=0.791 \\
p=0.009\end{array}$ & & & $\begin{array}{l}\mathrm{OR}=0.917 \\
p=0.557\end{array}$ & & \\
\hline 20 to $<30$ & $228(20.4)$ & $144(63.5)$ & 2.952 & 0.001 & $193(84.6)$ & 1.991 & 0.064 \\
\hline 30 to $<40$ & $752(67.2)$ & $429(57.0)$ & 2.287 & 0.007 & $703(93.5)$ & 5.181 & 0.000 \\
\hline 40 to $<50$ & $89(8.0)$ & $55(61.8)$ & 2.786 & 0.005 & $80(89.9)$ & 3.210 & 0.015 \\
\hline$\geq 50{ }^{\otimes}$ & $49(4.4)$ & $18(36.7)$ & & & $36(73.5)$ & & \\
\hline Parents' marital status & & $\begin{array}{l}\mathrm{OR}=1.23 \\
p=0.322\end{array}$ & & & $\begin{array}{l}\mathrm{OR}=73 \times 10^{6} \\
p=0.997\end{array}$ & & \\
\hline Married & $1,065(95.3)$ & $614(57.7)$ & 0.38 & 0.09 & $959(90.0)$ & 0.00 & 0.99 \\
\hline Divorced & $35(3.1)$ & $18(51.4)$ & 0.30 & 0.07 & $35(100)$ & 1.00 & 1.00 \\
\hline Widow/er ${ }^{\circledR}$ & $18(1.6)$ & $14(77.8)$ & & & $18(100)$ & & \\
\hline Parents' residence & & $\begin{array}{l}\mathrm{OR}=0.804 \\
p=0.151\end{array}$ & & & $\begin{array}{l}\mathrm{OR}=0.467 \\
p=0.001\end{array}$ & & \\
\hline Urban & $901(80.6)$ & $530(58.8)$ & 1.244 & 0.151 & $829(92.0)$ & 2.139 & 0.001 \\
\hline Rural & $217(19.4)$ & $116(53.5)$ & & & $183(84.3)$ & & \\
\hline Parents' employment & & $\begin{array}{l}\mathrm{OR}=1.17 \\
p=0.087\end{array}$ & & & $\begin{array}{l}\mathrm{OR}=0.995 \\
p=0.973\end{array}$ & & \\
\hline $\mathrm{No}{ }^{\oplus}$ & $285(25.5)$ & $157(55.1)$ & & & $256(89.8)$ & & \\
\hline Government agency & $741(66.3)$ & $425(57.4)$ & 1.09 & 0.51 & $674(91.0)$ & 1.14 & 0.57 \\
\hline Private sector & $49(4.4)$ & $39(79.6)$ & 3.18 & 0.00 & $44(89.8)$ & 0.99 & 0.99 \\
\hline Freelancer & $43(3.8)$ & $25(58.1)$ & 1.13 & 0.71 & $38(88.4)$ & 0.86 & 0.77 \\
\hline Parents' highest education & & $\begin{array}{l}\mathrm{OR}=0.828 \\
p=0.080\end{array}$ & & & $\begin{array}{l}\mathrm{OR}=0.95 \\
p=0.779\end{array}$ & & \\
\hline Elementary & $8(0.7)$ & $8(100.0)$ & $\begin{array}{l}128 \times \\
10^{6}\end{array}$ & 0.999 & $8(100 \%)$ & $\begin{array}{l}180 \times \\
10^{6}\end{array}$ & 0.999 \\
\hline High school & $18(1.6)$ & $9(50.0)$ & 0.790 & 0.622 & $13(72.2)$ & 0.291 & 0.023 \\
\hline Bachelors & $505(45.2)$ & $301(59.6)$ & 1.165 & 0.214 & $463(91.7)$ & 1.232 & 0.325 \\
\hline Postgraduate ${ }^{\circledR}$ & $587(52.5)$ & $328(55.9)$ & & & $528(89.9)$ & & \\
\hline Parents' income (LE) & & $\begin{array}{l}O R=0.69 \\
p=0.003\end{array}$ & & & $\begin{array}{l}\mathrm{OR}=2.54 \\
p<0.001\end{array}$ & & \\
\hline$\leq 3000$ & $594(53.1)$ & $368(62)$ & 1.441 & 0.003 & $517(87)$ & 0.393 & 0.00 \\
\hline >3000 & $524(46.9)$ & $278(53.1)$ & & & $495(94.5)$ & & \\
\hline Number of children & & $\begin{array}{l}\mathrm{OR}=1.11 \\
p=0.327\end{array}$ & & & $\begin{array}{l}\mathrm{OR}=2.51 \\
p<0.001\end{array}$ & & \\
\hline $1^{\oplus}$ & $207(18.5)$ & $116(56.0)$ & & & $163(78.7)$ & & \\
\hline $2-3$ & $808(72.3)$ & $466(57.7)$ & 1.069 & 0.671 & $756(93.6)$ & 3.924 & 0.000 \\
\hline $4-5$ & $89(8)$ & $55(61.8)$ & 1.269 & 0.358 & $79(88.8)$ & 2.133 & 0.044 \\
\hline$>5$ & $14(1.3)$ & $9(64.3)$ & 1.412 & 0.548 & $14(100.0)$ & $\begin{array}{l}436 \times \\
10^{6}\end{array}$ & 0.999 \\
\hline Children with chronic disease & & $\begin{array}{l}\mathrm{OR}=0.743 \\
p=0.239\end{array}$ & & & $\begin{array}{l}\mathrm{OR}=0.687 \\
p=0.430\end{array}$ & & \\
\hline Yes & $73(6.5)$ & $47(64.4)$ & 1.35 & 0.239 & $68(93.2)$ & 1.455 & 0.43 \\
\hline $\mathrm{No}^{\oplus}$ & $1045(93.5)$ & $599(57.3)$ & & & $944(90.3)$ & & \\
\hline
\end{tabular}


Table 1 Socio-demographic characteristics of survey respondents and their association with psychological impact of the pandemic on the parents and violent discipline against their children during the COVID-19 pandemic in Sohag governorate, Egypt, 2020 (Continued)

\begin{tabular}{|c|c|c|c|c|c|c|c|}
\hline Parameters & $\begin{array}{l}\text { Parents } \\
\text { respondents } \\
N=1118(\%)\end{array}$ & $\begin{array}{l}\text { Parents' IES-R score } \geq \\
33 \\
N=646(\%)\end{array}$ & OR & $p$ & $\begin{array}{l}\text { Parents' violent } \\
\text { discipline } \\
N=1012 .(\%)\end{array}$ & OR & $p$ \\
\hline $\begin{array}{l}\text { Other individuals living with } \\
\text { family }\end{array}$ & & $\begin{array}{l}\mathrm{OR}=0.815 \\
p=0.110\end{array}$ & & & $\begin{array}{l}\mathrm{OR}=1.88 \\
p=0.002\end{array}$ & & \\
\hline Yes & $385(34.4)$ & $235(61.0)$ & 1.22 & 0.11 & $334(86.8)$ & 0.531 & 0.002 \\
\hline $\mathrm{No}{ }^{\oplus}$ & $733(65.6)$ & $411(56.1)$ & & & $678(92.5)$ & & \\
\hline Total & 1118 & $646(57.8)$ & & & $1012(90.5)$ & & \\
\hline
\end{tabular}

${ }^{\circledR}$ Reference category

1118 parents who were residing in Egypt between March 25 and April 8, 2020, we found a high rate (90.5\%) of violent discipline with more than two-thirds of children experiencing severe physical violence. More than half of the respondents reported a moderate-to-severe psychological impact of COVID-19, which was significantly associated with a higher rate of violent discipline. These alarming findings warrant a timely comprehensive strategy to support families and protect children from violence during the continually evolving COVID-19 pandemic.

Table 2 Socio-demographic characteristics of children exposed to different types of violent discipline during the COVID-19 pandemic in Sohag governorate, Egypt, 2020

\begin{tabular}{|c|c|c|c|c|c|c|c|c|c|c|}
\hline Parameters & $\begin{array}{l}\text { Index } \\
\text { children } \\
N=1118 . \\
(\%)\end{array}$ & $\begin{array}{l}\text { Violent } \\
\text { discipline } \\
N=1012(\%)\end{array}$ & OR & $p$ & $\begin{array}{l}\text { Severe physical } \\
\text { discipline } \\
N=\mathbf{4 8 3} \text { (\%) }\end{array}$ & OR & $p$ & $\begin{array}{l}\text { Psychological } \\
\text { discipline } \\
N=992(\%)\end{array}$ & OR & $p$ \\
\hline Child gender & & $\begin{array}{l}\mathrm{OR}=1.35 \\
p=0.162\end{array}$ & & & $\begin{array}{l}\mathrm{OR}=0.527 \\
p<0.001\end{array}$ & & & $\begin{array}{l}\mathrm{OR}=1.79 \\
p=0.005\end{array}$ & & \\
\hline Male & $678(60.6)$ & $607(59.9)$ & 0.739 & 0.16 & $334(69.1)$ & 1.90 & 0.00 & $587(59.1)$ & 0.55 & 0.005 \\
\hline Female ${ }^{\circledR}$ & $440(39.4)$ & $405(40.1)$ & & & $149(31.9)$ & & & $405(40.9)$ & & \\
\hline Child age (years) & & $\begin{array}{l}\mathrm{OR}=1.28 \\
p<0.001\end{array}$ & & & $\begin{array}{l}\mathrm{OR}=0.80 \\
p<0.001\end{array}$ & & & $\begin{array}{l}\mathrm{OR}=1.23 \\
p=0.007\end{array}$ & & \\
\hline$<2$ & $149(13.3)$ & $110(10.8)$ & 0.452 & 0.013 & 65 (13.4) & 1.799 & 0.022 & $105(10.5)$ & 0.38 & 0.002 \\
\hline $2-<5$ & $286(25.6)$ & $271(26.7)$ & 2.89 & 0.004 & $148(30.6)$ & 2.493 & 0.000 & $271(27.3)$ & 2.89 & 0.004 \\
\hline $5-<8$ & $236(21.1)$ & $223(22)$ & 2.75 & 0.009 & $127(26.2)$ & 2.708 & 0.000 & $218(21.9)$ & 1.94 & 0.064 \\
\hline $8-<12$ & $324(29)$ & $302(29.8)$ & 2.20 & 0.021 & $106(21.9)$ & 1.130 & 0.594 & $292(29.4)$ & 1.46 & 0.235 \\
\hline$\geq 12$ & $123(11)$ & $106(10.4)$ & & & $37(7.6)$ & & & $106(86.2)$ & & \\
\hline Child birth order & & $\begin{array}{l}\mathrm{OR}=0.911 \\
p=0.561\end{array}$ & & & $\begin{array}{l}\mathrm{OR}=0.66 \\
p=0.000\end{array}$ & & & $\begin{array}{l}\mathrm{OR}=1.05 \\
p=0.758\end{array}$ & & \\
\hline $1^{\oplus}$ & $891(79.7)$ & $812(80.2)$ & & & $403(83.4)$ & & & 792 (79.8) & & \\
\hline $2-3$ & $158(14.1)$ & $136(13.4)$ & 0.601 & 0.04 & $63(13)$ & 0.810 & 0.232 & $136(13.7)$ & 0.77 & 0.309 \\
\hline $4-5$ & $50(4.5)$ & $45(4.4)$ & 0.876 & 0.78 & $14(2.8)$ & 0.475 & 0.021 & $45(4.5)$ & 1.12 & 0.807 \\
\hline$>5$ & $14(1.3)$ & $14(1.3)$ & $\begin{array}{l}157 \times \\
10^{6}\end{array}$ & 0.99 & $3(0.6)$ & 0.000 & 0.998 & $14(1.4)$ & $\begin{array}{l}201 \times \\
10^{6}\end{array}$ & 0.999 \\
\hline $\begin{array}{l}\text { Child education } \\
\text { level }\end{array}$ & & $\begin{array}{l}\mathrm{OR}=1.66 \\
p<0.001\end{array}$ & & & $\begin{array}{l}\mathrm{OR}=0.52 \\
p=0.001\end{array}$ & & & $\begin{array}{l}\mathrm{OR}=1.60 \\
p<0.001\end{array}$ & & \\
\hline $\mathrm{No}{ }^{\oplus}$ & $218(19.5)$ & $170(16.7)$ & & & $86(17.8)$ & & & 165 (16.6) & & \\
\hline Kindergarten & $345(30.9)$ & $321(31.7)$ & 3.8 & 0.00 & $198(11.8)$ & 2.06 & 0.00 & $316(31.8)$ & 3.50 & 0.000 \\
\hline Primary school & $435(38.9)$ & $418(41.3)$ & 6.9 & 0.00 & $161(33.3)$ & 0.90 & 0.55 & $408(41.1)$ & 4.85 & 0.000 \\
\hline Prep. school & $99(8.9)$ & $82(8.1)$ & 1.3 & 0.00 & $34(7)$ & 0.80 & 0.39 & $82(8.2)$ & 1.54 & 0.157 \\
\hline High school & $21(1.9)$ & $21(2.1)$ & $\begin{array}{l}456 \times \\
10^{6}\end{array}$ & 0.99 & $4(0.8)$ & 0.36 & 0.08 & $21(2.1)$ & $\begin{array}{l}518 \times \\
10^{6}\end{array}$ & 0.998 \\
\hline Total & 1118 & $1,012(90.5 \%)$ & & & $483(43.2 \%)$ & & & 992 (88.7\%) & & \\
\hline
\end{tabular}


Table 3 Reported discipline practice of parents toward their children during COVID-19 pandemic using adapted ICAST-P in Sohag governorate, Egypt, 2020

\begin{tabular}{|c|c|}
\hline Practice & $\begin{array}{l}\text { Respondents }(\%) \\
\text { (Total no. }=1118 \text { ) }\end{array}$ \\
\hline Non-violent discipline & $1094(97.9)$ \\
\hline 1. Explained & $308(28.2)$ \\
\hline 2. Told to stop something & $312(28.5)$ \\
\hline 3. Time out & $247(22.5)$ \\
\hline 8. Distracted & $127(11.6)$ \\
\hline 23. Took away privileges & $100(9.2)$ \\
\hline Moderate physical discipline & $768(68.7)$ \\
\hline 4. Shook child (>2 years) & $193(25.2)$ \\
\hline 6. Hit on buttocks w/object & $99(12.9)$ \\
\hline 7. Hit elsewhere w/object & $85(11)$ \\
\hline 9. Twisted ear & $84(10.9)$ \\
\hline 10. Knuckled back of head & $77(10)$ \\
\hline 11. Pulled hair & $83(10.8)$ \\
\hline 16. Others ${ }^{\mathrm{a}}$ & 0 \\
\hline 17. Painful kneel/stand & $20(2.6)$ \\
\hline 19. Spanked on buttocks w/bare hands & $33(4.3)$ \\
\hline 20. Spanked elsewhere w/bare hands & $45(5.9)$ \\
\hline 25. Pinched & $26(3.5)$ \\
\hline 26. Slapped face/back of head & $23(2.9)$ \\
\hline Severe physical discipline & $483(43.2)$ \\
\hline 5. Shook child (<2 years) & $135(28)$ \\
\hline 15. Kicked & $89(18.4)$ \\
\hline 21. Choked & $76(15.7)$ \\
\hline 30. Smother & $58(12)$ \\
\hline 31. Others ${ }^{a}$ & 0 \\
\hline 32. Beat up & $64(13.3)$ \\
\hline 33. Threaten with knife or gun & $61(12.6)$ \\
\hline 35. Others ${ }^{a}$ & 0 \\
\hline Psychological discipline & $992^{\#}(88.7)$ \\
\hline 12. Threatened to abandon & $134(13.5)$ \\
\hline 13. Shouted & $181(18.2)$ \\
\hline 14. Threatened to invoke spirits & $107(10.8)$ \\
\hline 18. Cursed & $23(2.3)$ \\
\hline 22. Threatened to send away & $121(12.2)$ \\
\hline 24. Insulted & $151(15.3)$ \\
\hline 27. Refused to speak & $51(5.2)$ \\
\hline 28. Withhold food & $103(10.3)$ \\
\hline 29. Told you wished he/she never born & $100(10.1)$ \\
\hline 34. Lock in a dark room & $21(2.1)$ \\
\hline Violent discipline & $1012(90.5)$ \\
\hline
\end{tabular}

${ }^{a}$ Chili pepper mouth, burn, and gave drug or alcohol

${ }^{\#}$ The sum does not add to 100 because of multiple responses
Evidence demonstrates that children are at increased risk of violence during times of public health emergencies [8]. Several reports during the current COVID-19 pandemic suggested that child abuse was exacerbated during this time of economic uncertainty and parents stress. In Jianli County (Hubei province, China), incidences of domestic violence reported to the police tripled during the lockdown in February: from 47 in 2019 to 162 in 2020 [20]. Fabbri et al., in their study that estimated the anticipated effect of COVID-19 on violent discipline against 1-14-year-old children at home using multivariable predictive regression models, reported that in Nigeria, Mongolia, and Suriname, under a "high restrictions" scenario, there would be a $35-46 \%$ increase in violent discipline scores, and under a "lower restrictions" scenario, there would be a $4-6 \%$ increase in violent discipline scores [21].

Results of the current study indicated that $90.5 \%$ of the studied children were subjected to violent disciplines. This rate is much higher than the results of a UNICEF study conducted in 2014, wherein $68.5 \%$ of the studied children were exposed to violent disciplines, [12] despite the reporting time-frame being markedly shorter ( 2 weeks) in the present study compared to the UNICEF study (3 months). Our results are also higher than the results of a meta-analysis of 38 reports from 96 countries on past-year prevalence of violence against children that indicated that a minimum of $50 \%$ or more of children in Asia, Africa, and Northern America experienced past-year violence [9].

However, a recent systematic review undertaken in 2019, of data of physical and emotional child maltreatment, sexual abuse, bullying and fighting, and violence in schools, retrieved using national population-based surveys, demonstrated that physical, sexual, and emotional violence against adolescents is widespread in the Arab region and that in many studies, the prevalence rates exceeded other regional or global estimates, including high rates of violent discipline [22]. The higher rate of violent disciplines in the current study may be explained by the fact that the aforementioned studies were conducted during usual conditions and were not related to a pandemic that necessitated lockdown. These high baseline rates of violence are alarming and are expected to increase during the COVID-19 pandemic. Studies conducted after the pandemic indicated that the rate of violent disciplines was increased during the pandemic in many countries [23], for example, in China, Xue et al. [23] analyzed over 1 million tweets related to family violence and COVID-19 from April 12 to July 16, 2020. Examining the data form the child helplines during the first 6 months of 2020, Petrowski et al. demonstrated that overall, the number of contacts to helplines in the USA seemed to have drastically increased since the 


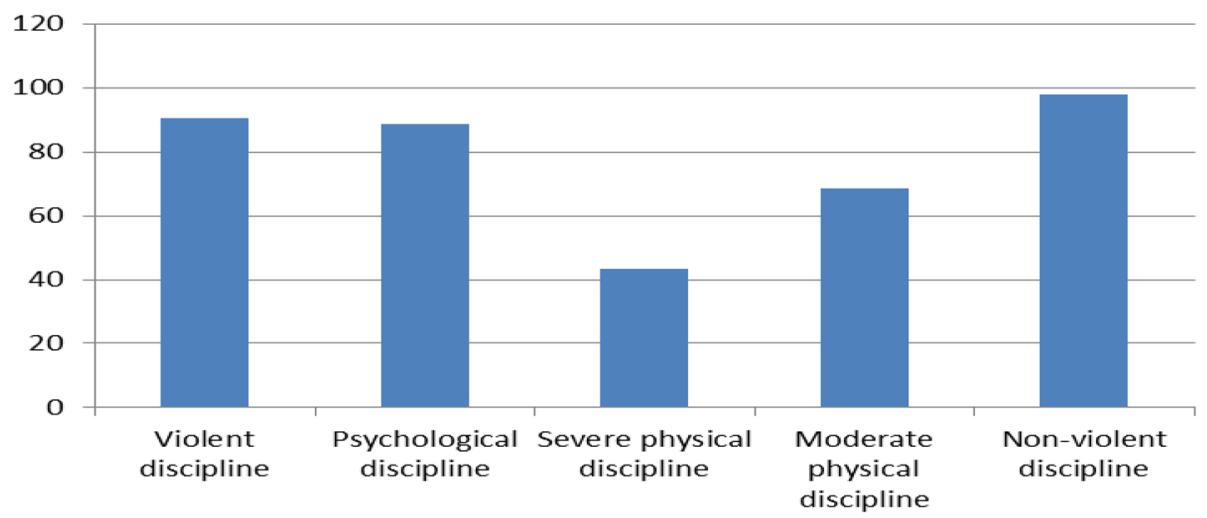

Fig. 2 Distribution of studied children according to the discipline practice reported by their parents during COVID-19 pandemic, Egypt, 2020, using adapted ICAST-P

beginning of the pandemic. However, they concluded that the number of contacts related to violence had increased in some countries, whereas it had decreased in others [24].

The present study identified certain sociodemographic risk factors of violence against children among parents and children. Poor parental education, lower family income, and small number of children are frequently reported as risk factors of violence against children. Our results are in agreement with these studies $[9,25]$. Our results are also in accordance with the research indicating that boys and girls are at equal risks of physical and psychological abuse, with a higher risk of sexual abuse for girls [9]; that boys are more exposed to violent discipline, particularly severe physical punishment; and that children under 4 years and adolescents are subject to a higher rate of violence that increases with age $[9,15,22]$. It is worth highlighting that violence against children is a multifactorial problem at levels, of not only individuals (parents and children) but also close relationships, community, and society $[9,22]$.

In the present study, $57.8 \%$ of respondents had a moderate-to-severe psychological impact (consistent with PTSD) related to the COVID-19 pandemic. These findings are in agreement with those in other studies; two studies in China reported PTSD in 53.8\% and 7.6\% of participants during the COVID-19 pandemic [26, 27]. PTSD was previously reported in $25.8 \%$ of respondents during the 2003 severe acute respiratory distress (SARS) outbreak in Singapore [28]. Moreover, a study that assessed the effect of the COVID-19-related lockdown on Tunisian women's mental health and gender-based violence indicated that more than half of the participants (57.3\%) reported extremely severe distress symptoms [29]. The higher rates of PTSD in our study, despite the significantly lower official number of cases and deaths related to COVID-19 in Egypt, may be attributed to differences in the sociodemographic background, pronounced impact of isolation measures, and higher public fears of infection and its adverse social and economic consequences, which might be exaggerated by the mass media and the deficiency of ventilators and intensive care facilities.

The identified risk factors of PTSD in this study are generally consistent with those in previous studies. Females and young people were reported to have a higher risk of PTSD [7, 26, 30]. In a Canadian study, participants with a lower income had a significantly higher rate of PTSD related to the SARS outbreak [30]. Individuals with lower income are more likely to be affected by any temporary decrease in income. Workers in the private sector appear to be more exposed to financial loss and redundancy compared to the more secure jobs in government agencies [7].

Table 4 Final model logistic regression analysis of psychological impact related to COVID-19 pandemic and violent discipline of parents against their children in Sohag governorate, Egypt, 2020

\begin{tabular}{|c|c|c|c|c|}
\hline & \multicolumn{2}{|l|}{ IES- R score } & \multirow[t]{2}{*}{$p$ value } & \multirow[t]{2}{*}{ OR $(95 \% \mathrm{Cl})$} \\
\hline & $<33$ & $\geq 33$ & & \\
\hline Participants & $472(42.2)$ & $646(57.8)$ & & \\
\hline Violent discipline & $382(80.9)$ & $630(97.5)$ & $p<0.001$ & $\mathrm{OR}=9.3(95 \% \mathrm{Cl} 5.4-16.0)$ \\
\hline Severe physical discipline & $136(28.8)$ & $347(53.7)$ & $p<0.001$ & $\mathrm{OR}=2.9(95 \% \mathrm{Cl} 2.3-3.7)$ \\
\hline Psychological discipline & 377 (79.9\%) & $615(95.2 \%)$ & $p<0.001$ & $\mathrm{OR}=5.0(95 \% \mathrm{Cl} 3.3-7.7)$ \\
\hline
\end{tabular}


The present study demonstrated a strong association between the adverse psychological impact of the COVID-19 pandemic in parents and rates of violence against children. Children of parents with COVID-19related PTSD were nine times more likely to be exposed to violence than those of parents with no or mild psychological impact. Based on previous reports of increased rates of PTSD with prolonged periods of quarantine [7], the magnitude of violence against children may markedly escalate with the protracted duration of the isolation measures associated with the COVID-19 pandemic.

Despite the challenges associated with the COVID-19 pandemic and the related isolation measures, some researchers have indicated that this situation can be an opportunity to enhance the relationship between parents and children. During lockdown times, children will benefit from keeping a sound, healthy, and productive daily schedule. Having a sense of aim and routine can help children and adults avoid negative feelings $[5,6,8]$. The findings of this study will contribute to the ongoing efforts of protecting children from violence during the rapidly expanding COVID-19 pandemic in Egypt and the world.

\subsection{Limitations}

The present study has some limitations. First, we used a snowball sampling strategy because of the limited resources and time-sensitivity of the COVID-19 pandemic. This sampling strategy does not rely on random selection; consequently, the study population does not mirror the actual characteristics of the general population. Second, the use of a web-based method for data collection might have restricted study participation to individuals with certain education and technology skills. This limits the generalizability of study findings, particularly among the less educated population. Third, for ethical reasons and age limits, violence against children was evaluated based on parents' reports only; children's reports were not studied. Fourth, it would have been ideal to carry out a follow-up study on the same study population to provide stronger evidence, investigate the effectiveness of intervention programs, and study the potential psychosocial impact of violence on the children. However, this is not applicable given the ethical mandate of anonymity and confidentiality. Fifth, the data were collected after only 1 month of the lockdown, and the expectation is that the rate of violence will escalate with prolonged lockdown and school closure. Finally, the pattern of violence described cannot be attributed to COVID-19 in view of the absence of information regarding the child disciplinary pattern prior to the pandemic.

\section{Conclusions}

This study provides an insight into the magnitude, characterization, and risk factors of violence against children during the COVID-19 pandemic in Egypt. The vast majority of the studied parents (90.5\%) reported practicing violent discipline against their children during the COVID-19 lockdown, shedding light on an alarming situation. Poor parental education, lower family income, and a large number of children were significant risk factors of violence against children. Notably, more than half of the studied parents experienced a moderate-to-severe psychological impact (consistent with PTSD) related to the COVID-19 pandemic, which was strongly associated with violence against children. Children of parents with COVID-19-related PTSD were nine times more likely to be exposed to violence than those of parents with no or mild psychological impact. These findings indicate the urgent need for increasing the public awareness regarding healthy parenting discipline and the best use of childhood time at home, as well as setting up a secure and easy system for parental counseling. Providing the parents with psychological support during this pandemic and training of healthcare professionals to regular screening for child abuse and neglect are highly recommended particularly those with poor socioeconomic status, to overcome the burden of the COVID-19 pandemic and isolation measures.

\section{Abbreviations}

CDC: Centers for Disease Control and Prevention; COVID-19: Coronavirus disease 2019; ICAST-P: Child Abuse Screening Tool-Parents; IES-R: Impact of Event Scale-Revised; ISPCAN: International Society for the Prevention of Child Abuse and Neglect; PTSD: Post-traumatic stress disorder; SARS: Severe acute respiratory distress syndrome; UNESCO: United Nations Educational, Scientific and Cultural Organization; UNICEF: The United Nations Children's Fund

\section{Acknowledgements}

Not applicable

\section{Authors' contributions}

EA prepared the online questionnaire, participated in its distribution and wrote the manuscript. SA contributed to the questionnaire distribution, statistical analysis of the data, and review of the final manuscript. RA contributed to reanalysis of the data and rewriting the manuscript based on the reviewers' comments. All authors have read and approved the manuscript.

\section{Funding}

No fund received.

\section{Availability of data and materials}

All data are available on demand from the corresponding author.

\section{Declarations}

Ethics approval and consent to participate

This study was approved by the institutional Research Ethics Committee, Faculty of Medicine, Sohag University, on 1 April 2020 and was carried out in accordance with the principles of the 1964 Declaration of Helsinki and its 2013 revision. Committee reference No.: not available. Informed consent of participants was obtained from the respondents by submitting the consent statement included in the online survey. 


\section{Consent for publication}

Not applicable

\section{Competing interests}

All authors declared no conflict of interest.

\section{Author details}

${ }^{1}$ Public Health and Community Medicine Department, Sohag University,

Sohag, Egypt. 'Department of Pediatrics, Sohag University, Sohag, Egypt.

Received: 24 September 2020 Accepted: 3 April 2021

Published online: 20 April 2021

\section{References}

1. Rajkumar RP. COVID-19 and mental health: a review of the existing literature. Asian J Psychiatr. 2020:52:102066.

2. Nicola M, Alsafi Z, Sohrabi C, Kerwan A, Al-Jabir A, losifidis C, et al. The socio-economic implications of the coronavirus and COVID-19 pandemic: a review. Int J Surg (London, England). 2020;78:185-93.

3. Wilder-Smith A, Freedman DO. Isolation, quarantine, social distancing and community containment: pivotal role for old-style public health measures in the novel coronavirus (2019-nCoV) outbreak. J Travel Med. 2020;27(2).

4. UNESCO. COVID-19 educational disruption and response: United Nations Educational, Scientific and Cultural Organization (UNESCO); 2020. Available from: https://en.unesco.org/covid19/educationresponse

5. Viner RM, Russell SJ, Croker H, Packer J, Ward J, Stansfield C, et al. School closure and management practices during coronavirus outbreaks including COVID-19: a rapid systematic review. Lancet Child Adolesc Health. 2020;4(5): 397-404.

6. Bradbury-Jones C, Isham L. The pandemic paradox: the consequences of COVID-19 on domestic violence. J Clin Nurs. 2020;29(13-14):2047-9.

7. Brooks SK, Webster RK, Smith LE, Woodland L, Wessely S, Greenberg N, et al. The psychological impact of quarantine and how to reduce it: rapid review of the evidence. Lancet. 2020;395(10227):912-20.

8. Cluver L, Lachman JM, Sherr L, Wessels I, Krug E, Rakotomalala S, et al. Parenting in a time of COVID-19. Lancet. 2020;395(10231):e64.

9. Hillis S, Mercy J, Amobi A, Kress H. Global prevalence of past-year violence against children: a systematic review and minimum estimates. Pediatrics. 2016;137(3):e20154079

10. Norman RE, Byambaa M, De R, Butchart A, Scott J, Vos T. The long-term health consequences of child physical abuse, emotional abuse, and neglect: a systematic review and meta-analysis. PLoS Med. 2012;9(11):e1001349.

11. Tran QA, Dunne MP, Vo TV, Luu NH. Adverse childhood experiences and the health of university students in eight provinces of Vietnam. Asia Pac J Public Health. 2015;27(8 Suppl):26s-32s.

12. NCCM, UNICEF. Violence against children in Egypt: quantitative survey and qualitative study in Cairo. Cairo: Alexandria and Assuit; 2015.

13. Peterman A, Potts A, O'Donnell M, Thompson K, Shah N, Oertelt-Prigione S, et al. Pandemics and violence against women and children. Center for Global Development working paper; 2020. p. 528.

14. MOHP. COVID-19 statistics in Egypt Egyptian Ministry of Health and population (MOHP); 2020. Available from: https://www.care.gov.eg/EgyptCa re

15. Runyan DK, Dunne MP, Zolotor AJ, Madrid B, Jain D, Gerbaka B, et al. The development and piloting of the ISPCAN child abuse screening tool-parent version (ICAST-P). Child Abuse Negl. 2009;33(11):826-32.

16. Hambleton RK, Merenda PF, Spielberger CD. Adapting educational and psychological tests for cross-cultural assessment: Psychology Press; 2004

17. Weiss DS. The impact of event scale: revised. Cross-cultural assessment of psychological trauma and PTSD: Springer; 2007. p. 219-38.

18. Creamer M, Bell R, Failla S. Psychometric properties of the impact of event scale - revised. Behav Res Ther. 2003;41(12):1489-96.

19. Meinck F, Boyes ME, Cluver L, Ward CL, Schmidt P, DeStone S, et al. Adaptation and psychometric properties of the ISPCAN child abuse screening tool for use in trials (ICAST-trial) among south African adolescents and their primary caregivers. Child Abuse Negl. 2018;82:45-58.

20. Lee J. Mental health effects of school closures during COVID-19. Lancet Child Adolescent Health. 2020;4:421

21. Fabbri C, Bhatia A, Petzold M, Jugder M, Guedes A, Cappa C, et al. Modelling the effect of the COVID-19 pandemic on violent discipline against children. Child Abuse Negl. 2020:104897. https://www.sciencedirect. com/science/article/pii/S0145213420305524?via\%3Dihub.

22. Elghossain T, Bott S, Akik C, Ghattas H, Obermeyer CM. Prevalence of key forms of violence against adolescents in the Arab region: a systematic review. J Adolesc Health. 2019;64(1):8-19.

23. Xue J, Chen J, Chen C, Hu R, Zhu T. The hidden pandemic of family violence during COVID-19: unsupervised learning of tweets. J Med Internet Res. 2020;22(11):e24361.

24. Petrowski N, Cappa C, Pereira A, Mason H, Daban RA. Violence against children during COVID-19 assessing and understanding change in use of helplines. Child Abuse Negl. 2020;104757.

25. Alyahri A, Goodman R. Harsh corporal punishment of Yemeni children: occurrence, type and associations. Child Abuse Negl. 2008;32(8):766-73.

26. Wang C, Pan R, Wan X, Tan Y, Xu L, Ho CS, et al. Immediate psychological responses and associated factors during the initial stage of the 2019 coronavirus disease (COVID-19) epidemic among the general population in China. Int J Environ Res Public Health. 2020;17(5):1729.

27. Zhang Y, Ma ZF. Impact of the COVID-19 pandemic on mental health and quality of life among local residents in Liaoning Province, China: a crosssectional study. Int J Environ Res Public Health. 2020;17(7):2381.

28. Sim K, Huak Chan Y, Chong PN, Chua HC, Wen SS. Psychosocial and coping responses within the community health care setting towards a national outbreak of an infectious disease. J Psychosom Res. 2010;68(2):195-202.

29. Sediri S, Zgueb Y, Ouanes S, Ouali U, Bourgou S, Jomli R, et al. Women's mental health: acute impact of COVID-19 pandemic on domestic violence. Arch Womens Ment Health. 2020:1-8.

30. Hawryluck L, Gold WL, Robinson S, Pogorski S, Galea S, Styra R. SARS control and psychological effects of quarantine, Toronto, Canada. Emerg Infect Dis. 2004;10(7):1206-12.

\section{Publisher's Note}

Springer Nature remains neutral with regard to jurisdictional claims in published maps and institutional affiliations.

\section{Submit your manuscript to a SpringerOpen ${ }^{\circ}$ journal and benefit from:}

- Convenient online submission

- Rigorous peer review

- Open access: articles freely available online

High visibility within the field

- Retaining the copyright to your article

Submit your next manuscript at $>$ springeropen.com 